\title{
Unexpected diagnosis of a right iliac fossa mass in the elderly
}

\author{
Salem Bouomrani ${ }^{1,2 *}$, Fatma Rekik ${ }^{1,2}$ and Souad Yahyaoui ${ }^{1}$ \\ ${ }^{1}$ Department of Internal medicine, Military Hospital of Gabes, Gabes 6000, Tunisia \\ ${ }^{2}$ Sfax Faculty of Medicine, University of Sfax, Sfax 3029, Tunisia
}

\begin{abstract}
Introduction: The diagnosis of pains and masses of the right iliac fossa (RIF) represents a real diagnostic challenge for clinicians, particularly in the elderly, mainly because of the important clinical polymorphism at this age, and anatomical changes caused by senescence.

We are reporting an original observation of an unexpected diagnosis of a RIF mass in the elderly.

Case report: A 87-year-old Tunisian woman, without pathological medical history, was hospitalized in our department for exploration of a painful RIF mass evolving for two weeks. The somatic examination found a mass of the right iliac fossa, of hard consistency, tense, fixed in the deep plane, without fever or deterioration of the general state, or local cutaneous signs. The biology showed leukocytosis at $12800 / \mathrm{mm} 3$ with $75 \%$ neutrophils, high erythrocyte sedimentation rate at $83 \mathrm{~mm} / \mathrm{H} 1$, and C-reactive protein at $22 \mathrm{mg} / 1$.
\end{abstract}

Abdominal ultrasound and CT concluded at acute cholecystitis (AC). Surgery confirmed the diagnosis of acute gangrenous cholecystitis with significant dilatation of gallbladder that was prolapsed in the RIF.

Conclusion: As rare as it is, AC as possible etiology of RIF mass in elderly must be known to avoid diagnosis delay and improve the prognosis. To the best of our knowledge such a presentation was reported only once previously.

\section{Introduction}

The diagnosis of pains and masses of the right iliac fossa (RIF) represents a real diagnostic challenge for clinicians, particularly in the elderly, mainly because of the important clinical polymorphism at this age (unusual forms, asthenic/apathic forms, complicated forms), and anatomical changes caused by senescence [1-3].

Acute cholecystitis (AC) is a fairly common surgical emergency in the elderly who is characterized by significant mortality [4]. Its diagnosis is not always easy in these subjects because of several clinical and/or paraclinical particularities [5].

We are reporting an original observation of AC in elderly presented as a RIF mass.

\section{Case report}

An 87-year-old Tunisian woman, without pathological medical history, was hospitalized in our department for exploration of a painful RIF mass evolving for two weeks.

The somatic examination found a mass of the right iliac fossa, of hard consistency, tense, fixed in the deep plane, without fever or deterioration of the general state, or local cutaneous signs.

The biology showed leukocytosis at $12800 / \mathrm{mm}^{3}$ with $75 \%$ neutrophils, high erythrocyte sedimentation rate at $83 \mathrm{~mm} / \mathrm{H} 1$, and C-reactive protein at $22 \mathrm{mg} / \mathrm{l}$.

The other basic bioassays were without abnormalities: hemoglobin, platelets, liver enzymes, creatinine, blood glucose, serum calcium, ionogram, muscle enzymes, and serum protein electrophoresis. Chest $\mathrm{X}$-ray and electrocardiogram were normal. The abdominal ultrasound showed the existence at the level of the RIF of an oval formation of $14 \mathrm{~cm}$ long axis, with heterogeneous echostructure, fluid center, and a liquidliquid level. It contained a $4.5 \mathrm{~cm}$ diameter hyperechoic, laminated, and mobile arciform image, followed by a posterior shadow cone (Figure 1).

This mass had a thickened and laminated wall of $2.5 \mathrm{~cm}$ and was surrounded by a localized and compartmentalised fluid effusion (Figures 2 and 3). The liver was normal in size and echostructure, inta- and extrahepatic bile ducts were thin, without visualization of the gallbladder at its normal lodge. The echographic aspect of this mass recalled an acute lithiasic pyocholecyst. The abdominal computed tomography (CT) showed the presence at the level of the RIF of an enormous mass measuring $14 \mathrm{~cm}$ of long axis, of liquid density, and pushing back the digestive structures which seem of normal aspect. At the center of this mass we noted the existence of a large stratified calculation of $4 \mathrm{~cm}$ diameter (Figure 4). This mass had a thickened wall with very discrete peripheral enhancement after contrast injection (Figure 5). The appearance of the liver was normal and without dilation

${ }^{\star}$ Correspondence to: Salem Bouomrani, Department of Internal medicine, Military Hospital of Gabes, Gabes 6000, Tunisia, E-mail: salembouomrani@yahoo.fr

Key words: acute cholecystitis, elderly, right iliac fossa, mass, tumor, acute abdomen

Received: December 03, 2018; Accepted: December 10, 2018; Published: December 12, 2018 
of bile ducts. At the end of this assessment, the preoperative diagnosis was acute cholecystitis located in the RIF. The surgical intervention confirmed the imaging data and revealed a significant dilatation of gallbladder that was prolapsed in the RIF. The macroscopic aspect and the histological examination were favor acute gangrenous cholecystitis (Figure 6).

\section{Discussion}

Tumor pathology of RIF in the elderly is by far dominated by complicated acute appendicitis of appendicular abscesses, coecal diverticulitis with peridiverticulitis, and right colon cancers [6,7]. Inflammatory colitis (Crohn's disease and ulcerative colitis) complicated by abscesses or inflammatory pseudotumors, ileocaecal tuberculosis, gynecological causes in women (adnexal infections and ovarian tumors), and hematomas of the iliac fossa are more rarely noted $[3,8,9]$.

Sometimes diagnostic surprises can be discovered during investigations and/or surgical procedures for RIF masses in the elderly such as: pedunculated hepatocellular carcinoma, amoebic liver abscess, Spiegel hernia, pseudotumoral actinomycosis, pharmocobezoar, ileo-

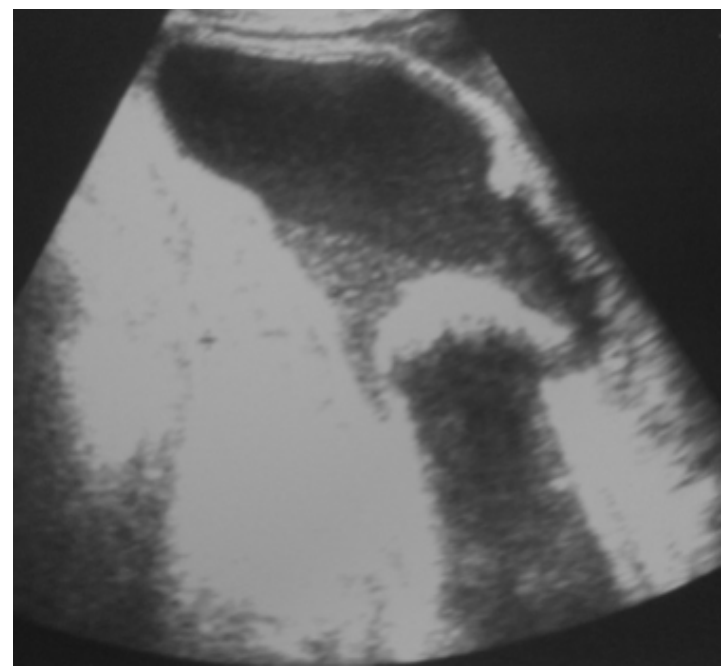

Figure 1. Abdominal ultrasound: heterogeneous mass, with a liquid-liquid level and a hyperechoic, laminated arciform image, followed by a posterior shadow cone

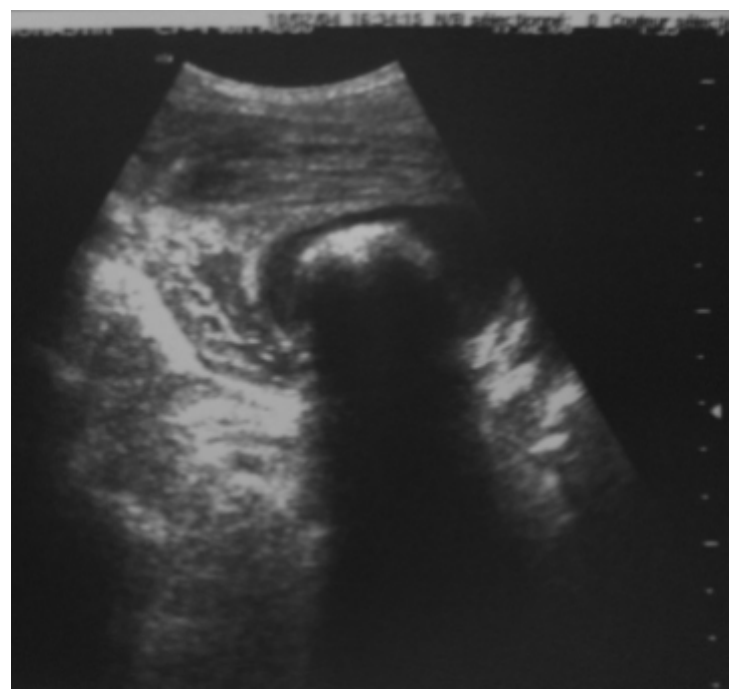

Figure 2. Abdominal ultrasound: marked thickened and laminated wall of the mass

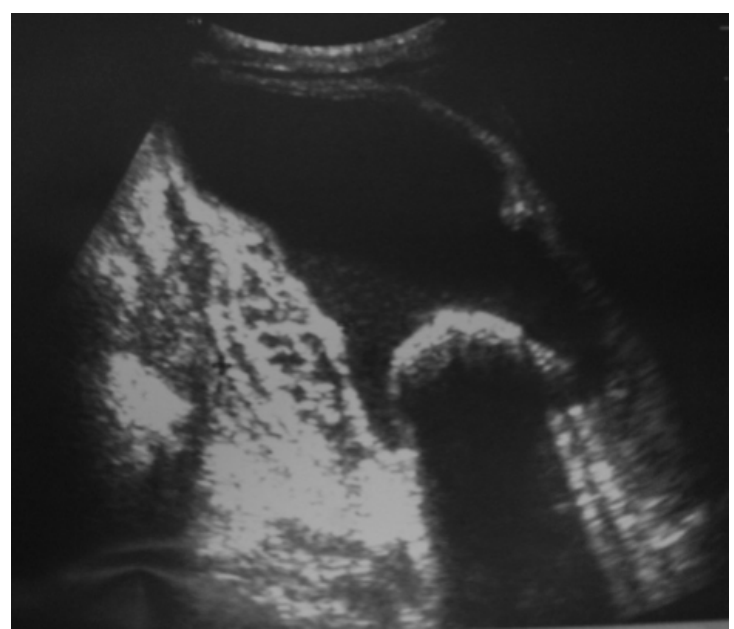

Figure 3. Abdominal ultrasound: localized and compartmentalised fluid effusion surrounding the mass

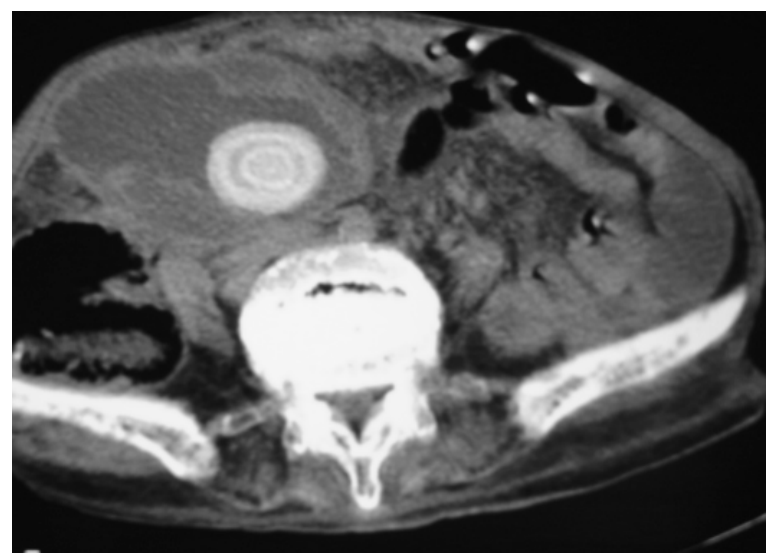

Figure 4. Axial abdominal CT without contrast injection: enormous mass of liquid density in the right iliac fossa with a large stratified calculation

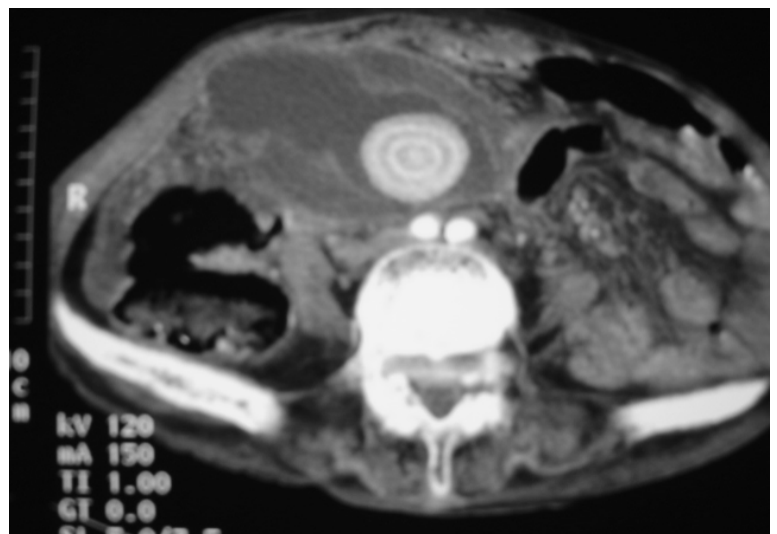

Figure 5. Axial abdominal CT with contrast injection: thickened wall of the right iliac fossa mass with discrete peripheral enhancement

caecal intussusception, mucocele of the appendix, mesenteric teratoma, or unusually very dilated or ptosed gallbladder [6,10-18].

The considerable dilations/ptosis of the gallbladder are exceptional: only 158 cases were noted in the large series of 4575 pathological gallbladders of Baumgartner CJ (3.45\%) [18]. This dilations/ptosis of the gallbladder may be complicated by unusual acute cholecystitis manifesting as pain and/or swelling of the RIF. 


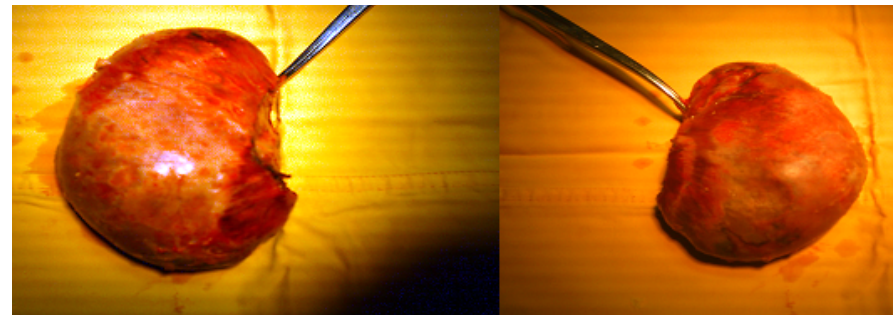

Figure 6. Postoperative macroscopic appearance of acute gangrenous cholecystitis

A single case of AC with dilated gallbladder simulating a RIF tumor in an 84-year-old woman was previously reported in the international medical literature [9]. Our observation is, to our knowledge, the second reporting such a presentation. Medical imaging, in particular abdominal computed tomography, plays a crucial role in the characterization and the diagnosis of certainty of these masses of RIF mass in the elderly [7]. Abdominal ultrasonography, although often indicated as a first-line examination, is not sufficient on its own for the diagnosis of certainty of RIF masses; However, it allows to identify the organ of origin of the swelling in more than $90 \%$ of cases [1].

\section{Conclusion}

As rare as it is, AC as possible etiology of RIF mass in elderly must be known. This knowledge will avoid diagnosis delay, and improve the prognosis of this disease, potentially fatal in geriatrics.

Our case is, to the best of our knowledge, the second case of AC presented as a mass of the RIF in the elderly.

\section{Conflicts of interest}

None.

\section{References}

1. Millard FC, Collins MC, Peck RJ (1991) Ultrasound in the investigation of the right iliac fossa mass. Br J Radiol 64: 17-19. [Crossref]

2. Leuthauser A, McVane B (2016) Abdominal pain in the geriatric patient. Emerg Med Clin North Am 34: 363-75.
3. Tubiana JM, Sebag A, Arrive L, Duron JJ (2003) Gastrointestinal tract in the elderly. $J$ Radiol 84: 1837-1844.

4. Wiggins T, Markar SR, Mackenzie H, Jamel S, Askari A, et al. (2018) Evolution in the management of acute cholecystitis in the elderly: population-based cohort study. Surg Endosc 32: 4078-4086. [Crossref]

5. Polyanskiy MB, Nazarenko DP, Ishunina TA (2017) Age-related peculiarities of acute cholecystitis. Adv Gerontol 30: 291-297.

6. Moser JJ, Barras JP, Baer HU (1994) Diagnostic surprises in apparently inflammatory masses of the right iliac fossa. Helv Chir Acta 60: 653-656.

7. Gammeri E, Catton A, van Duren BH, Appleton SG, van Boxel GI (2016) Towards an evidence-based management of right iliac fossa pain in the over 50 -year-old patient Ann R Coll Surg Engl 98: 496-499.

8. Bromberg SH, Faroud S, de Castro FF, Morrone N, de Godoy AC, et al. (2001) Isolated ileocecal tuberculosis simulating malignant neoplasia and Crohn's disease. Rev Assoc Med Bras 47: 25-8. [Crossref]

9. Genell S, Jonsson K (1976) Dilatation of the gall-bladder simulating a tumour in the right iliac fossa. A case report. Rofo 124: 388-389.

10. Campos Franco J, Mallo González N, Barros Alcalde P, Pazos González G, González Quintela A (2008) Pedunculated hepatocellular carcinoma presenting as a mass in the right iliac fossa. Rev Esp Enferm Dig 100: 718-719. [Crossref]

11. Ratnasamy V, Thirunavukarasu K, Selvam K, Arumugam M (2016) Amoebic liver abscess: an unusual cause for a right iliac fossa mass: a case report. BMC Infect Dis 16: 741. [Crossref]

12. Newman TH, Caine EA, Lynes K, Sebastian J (2017) An uncommon right iliac fossa mass in an older woman. BMJ 358: $\mathrm{j} 3279$.

13. Leach TD, Sadek SA, Mason JC (2002) An unusual abdominal mass in a rena transplant recipient. Transpl Infect Dis 4: 218-22. [Crossref]

14. Khera G, Lord R, Grey K, Maitra D (2008) An unusual case of right iliac fossa mass-Pharmacobezoar mimicking inflammatory bowel disease. Colorectal Dis 10: 95-96. [Crossref]

15. Mc Laughlin SJ, Gray JG, Braithwaite M (1986) Diagnosis of a right iliac fossa mass by computed tomography. Br J Radiol 59: 623-624. [Crossref]

16. Vashistha N, Aggarwal B, Singhal D (2017) Incidentaloma in the right iliac fossa. JAMA Surg 152: 405-406.

17. Neeralagi CS, Surag KR, Kumar Y, Lakkanna S, Raj P (2017) Mesenteric teratoma in elderly female: A Rare case report. J Clin Diagn Res 11: PD01-PD02. [Crossref]

18. Baumgartner CJ (1929) Pathological lesions of the gall bladder. Surg Gyn Obstet 49: 780

Copyright: (C2018 Bouomrani S. This is an open-access article distributed under the terms of the Creative Commons Attribution License, which permits unrestricted use, distribution, and reproduction in any medium, provided the original author and source are credited. 